Research Article Human and Medical Genetics

\title{
A novel TBX5 mutation predisposes to familial cardiac septal defects and atrial fibrillation as well as bicuspid aortic valve
}

\author{
Wei-Feng Jiang, ${ }^{1, *}$, Ying-Jia Xu',*, Cui-Mei Zhao ${ }^{3}$, Xin-Hua Wang ${ }^{4}$, Xing-Biao Qiu ${ }^{1}, \mathrm{Xu} \mathrm{Liu}^{1}$, \\ Shao-Hui $\mathrm{Wu}^{1}$ and Yi-Qing Yang ${ }^{2,5,6}$ (D)

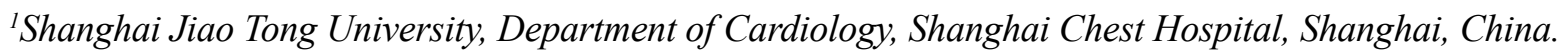 \\ ${ }^{2}$ Fudan University, Department of Cardiology, Shanghai Fifth People's Hospital, Shanghai, China. \\ ${ }^{3}$ Tongji University School of Medicine, Department of Cardiology, Tongji Hospital, Shanghai, China. \\ ${ }^{4}$ Shanghai Jiao Tong University School of Medicine, Department of Cardiology, Renji Hospital, \\ Shanghai, China. \\ ${ }^{5}$ Fudan University, Cardiovascular Research Laboratory, Shanghai Fifth People's Hospital, \\ Shanghai, China. \\ ${ }^{6}$ Fudan University, Central Laboratory, Shanghai Fifth People's Hospital, Shanghai, China.
}

\begin{abstract}
TBX5 has been linked to Holt-Oram syndrome, with congenital heart defect (CHD) and atrial fibrillation (AF) being two major cardiac phenotypes. However, the prevalence of a TBX5 variation in patients with CHD and AF remains obscure. In this research, by sequencing analysis of TBX5 in 178 index patients with both $\mathrm{CHD}$ and AF, a novel heterozygous variation, NM_000192.3: c.577G>T; p.(Gly193*), was identified in one index patient with CHD and $\mathrm{AF}$ as well as bicuspid aortic valve (BAV), with an allele frequency of approximately $0.28 \%$. Genetic analysis of the proband's pedigree showed that the variation co-segregated with the diseases. The pathogenic variation was not detected in 292 unrelated healthy subjects. Functional analysis by using a dual-luciferase reporter assay system showed that the Gly193*-mutant TBX5 protein failed to transcriptionally activate its target genes $M Y H 6$ and NPPA. Moreover, the mutation nullified the synergistic transactivation between TBX5 and GATA4 as well as NKX2-5. Additionally, whole-exome sequencing analysis showed no other genes contributing to the diseases. This investigation firstly links a pathogenic variant in the TBX5 gene to familial CHD and AF as well as BAV, suggesting that CHD and AF as well as BAV share a common developmental basis in a subset of patients.
\end{abstract}

Keywords: Congenital heart disease, atrial fibrillation, bicuspid aortic valve, molecular genetics, TBX5.

Received: May 07, 2020; Accepted: September 19, 2020.

\section{Introduction}

As the most prevalent type of human birth defect, congenital heart defect (CHD) occurs in about $1 \%$ of all live neonates, accounting for nearly a third of all forms of developmental abnormalities (Benjamin et al., 2019; OliveiraBrancati et al., 2020). Although minor CHD may resolve spontaneously (Benjamin et al., 2019), serious CHD may lead to poor health-related quality of life (Amedro et al., 2018, 2019; Boukovala et al., 2019), reduced exercise capacity (Müller et al., 2018; Abassi et al., 2019; Smith et al., 2019), abnormal nervous development or brain injury (Peyvandi et al., 2018, 2019; Khanna et al., 2019), hemorrhagic or ischemic stroke (Bokma et al., 2018; Giang et al., 2018; Pedersen et al., 2019), pulmonary hypertension (Brida and Gatzoulis, 2018; Dimopoulos et al., 2018; Kaemmerer et al., 2018; Pascall and Tulloh, 2018), acute kidney injury or renal dysfunction (Lui et al., 2017; Gist et al., 2018), infective endocarditis (Jortveit et al., 2018; Tutarel et al., 2018; Cahill et al., 2019), cardiac dysfunction or congestive heart failure (Gilbert et al., 2018;

Send correspondence to Yi-Qing Yang. Fudan University, Cardiovascular Research Laboratory, Shanghai Fifth People's Hospital, 801 Heqing Road, Shanghai 200240, China. E-mail: yangyiqing @5thhospital.com (YQY).

*These authors contributed equally to this work.
Lal et al., 2018; Sabanayagam et al., 2018; Chan et al., 2019), ventricular or supraventricular dysrhythmia (Labombarda et al., 2017; Barry et al., 2018; Hernández-Madrid et al., 2018; Fuchs et al., 2019), and death (Lynge et al., 2018; Moore et al., 2018; Yu C et al., 2018). Although vast advance in cardiac surgery allows over $90 \%$ of CHD newborns to survive into adulthood, it results in an increasing adult CHD population, and mow CHD adults outnumber CHD children (Bouma and Mulder, 2017; Benjamin et al., 2019). Moreover, the late complications and mortality substantially increase in adult CHD patients (Bouma and Mulder, 2017; Spector et al., 2018; Trusty et al., 2018). Despite clinical importance, the etiologies of CHD in the majority of cases are still elusive.

Cardiogenesis undergoes a highly complex biological process, and both environmental and genetic pathogenic factors can perturb this finely regulated process, leading to CHD (Patel and Burns, 2013; Pierpont et al., 2018; Shabana et al., 2020). The well-established environmental factors underlying CHD include maternal conditions (such as innutrition, viral infection and endocrine disorder) and exposures to toxic chemicals, therapeutic drugs, or ionizing radiation during pregnancy (Patel and Burns, 2013). However, increasing studies underscore the genetic defects underpinning CHD, and variations in over 70 genes, encompassing those encoding transcription 
factors, signaling molecules, and sarcomeric proteins, have been involved in CHD (Bashamboo et al., 2018; Cantù et al., 2018; Jaouadi et al., 2018; Li et al., 2018a,c; Lombardo et al., 2018; Manheimer et al., 2018; Pierpont et al., 2018; Qiao et al., 2018; Razmara and Garshasbi, 2018; Stephen et al., 2018; $\mathrm{Xu}$ et al., 2018; Yu Z et al., 2018; Alankarage et al., 2019; Gao et al., 2019; Kalayinia et al., 2019, 2020; Ma et al., 2019; Wang J et al., 2019, Wang Z et al., 2019; Watkins et al., 2019; Zhu et al., 2019; Faucherre et al., 2020; Shabana et al., 2020; Zhao et al., 2020). Among the recognized CHD-causative genes, the majority code for cardiac transcription factors, encompassing TBX5, GATA4, and NKX2-5 (Li and Yang, 2017). Nevertheless, the genetic determinants underlying CHD in a large proportion of cases remain to be unveiled.

Interestingly, $T B X 5$ variations have recently been involved in atrial fibrillation (AF), the most common sustained cardiac arrhythmia (January et al., 2014). Postma et al., (2008) reported that a $T B X 5$ gain-of-function mutation caused an atypical Holt-Oram syndrome (HOS), with AF being the predominant clinical phenotype. Ma et al., (2016) identified multiple loss-of-function mutations in TBX5 in multiple patients affected with AF. Wang et al., (2016) found a novel loss-of-function mutation in $T B X 5$ in a case with AF. Guo et al., (2016) uncovered a new TBX5 loss-of-function mutation in an index patient with idiopathic AF. These observational results highlight the pronounced genetic heterogeneity of $\mathrm{CHD}$ and $\mathrm{AF}$, which makes it justifiable to investigate the prevalence of $T B X 5$ variations in patients with both CHD and $\mathrm{AF}$, and unveil the molecular mechanism of CHD and AF resulted from novel TBX5 variations.

\section{Material and Methods}

\section{Study participants}

This study subjects comprised 178 unrelated adult patients suffering from both $\mathrm{CHD}$ and AF, who were consecutively recruited between February 2015 and March 2019 from the Chinese Han population. Diagnosis of CHD and various kinds of AF was made as described previously (Wang et al., 2016; Li et al., 2018b; Ma et al., 2019). The patients with rheumatic heart disease, ischemic heart disease, essential hypertension, or other recognized risk factors for AF were excluded. The patients with AF occurred after cardiac surgery were also ruled out from the present investigation. If available, the relatives of the probands were also enrolled. The control individuals were 292 unrelated adult healthy persons, who were enlisted from the same geographic area during the same time period. The healthy controls were matched with the affected individuals for ethnicity, sex and age. All study participants were subject to comprehensive medical evaluation, including familial histories, medical histories, physical examination, trans-thoracic echocardiogram, standard 12-lead electrocardiogram, and routine biological tests. This investigation was conducted in accordance with the ethical principles stated in the Declaration of Helsinki. The protocol used in this study was reviewed and approved by the Human Ethics Committee of the Shanghai Chest Hospital, Shanghai, China. Informed consent was obtained from the study participants prior to sample collection.

\section{Genetic analyses}

Blood samples were collected from each study subject. Genomic DNA of each test subject was purified from blood cells with the Wizard Genomic DNA Purification Kit (Promega, Madison, WI, USA). The coding exons and splicing donors/ acceptors of $T B X 5$ were amplified from each study participant's genomic DNA by polymerase chain reaction (PCR) for a variation scan by PCR-sequencing. The PCR primers were designed as described elsewhere (Zhang et al., 2015). Each PCR mixture was prepared in a thin-walled PCR tube with a total volume of $25 \mu \mathrm{L}$ containing $50 \mathrm{ng}$ of genomic DNA, 0.2 $\mathrm{mM}$ dNTPs (Qiagen, Hilden, Germany), $1 \times$ Buffer (Qiagen), $1 \times$ Q solution (Qiagen), $0.5 \mu \mathrm{M}$ of each primer, and $0.02 \mathrm{U} / \mu \mathrm{L}$ of HotStar Taq DNA Polymerase (Qiagen). PCR was carried out on a Veriti ${ }^{\circledR}$ 96-Well Thermocycler (Applied Biosystems, Foster, CA, USA). The PCR program was set as follows: initial pre-denaturation at $95^{\circ} \mathrm{C}$ for $15 \mathrm{~min}$ followed by 35 thermal cycles of denaturation at $95^{\circ} \mathrm{C}$ for $30 \mathrm{~s}$, annealing at $62^{\circ} \mathrm{C}$ for $30 \mathrm{~s}$ and extension at $72^{\circ} \mathrm{C}$ for $1 \mathrm{~min}$, with final extension at $72{ }^{\circ} \mathrm{C}$ for $8 \mathrm{~min}$. The amplified products were fractionated by electrophoresis on a $1.2 \%$ agarose gel, and isolated utilizing the QIAquick Gel Extraction Kit (Qiagen). The purified amplicons were subjected to PCR-sequencing under an ABI 3730 XL DNA Analyzer (Applied Biosystems), with the BigDye $^{\circledR}$ Terminator v3.1 Cycle Sequencing Kit (Applied Biosystems) following the manufacturer's instructions. The detected sequence variant was validated by bi-directional re-sequencing of an independent PCR-generated amplicon from the same subject. For an identified TBX5 variation, the 1000 Genomes Project database (http://www.1000genomes. org), the Genome Aggregation Database (https://gnomad. broadinstitute.org), and the Single Nucleotide Polymorphism database (http://www.ncbi.nlm.nih.gov/snp) were queried to check its novelty.

In addition, in order to rule out the potential causative effects of other genes on the diseases, whole-exome sequencing (WES) analysis of the mutation carrier's family members was performed as described previously (Xu et al., 2019). In brief, $2 \mu \mathrm{g}$ of DNA from each family member was utilized to construct an exome library with the SureSelectXT Human All Exon V6 Kit (Agilent Technologies, Santa Clara, CA, USA), which was sequenced on the Solexa Genome Analyzer (GA) IIx platform (Illumina, San Diego, CA, USA), according to the manufacturer's protocols. Raw image files were processed by the Illumina pipeline to call bases and generate the reads set. By using SOAPaligner, reads were aligned with the human reference genome. Variations of single nucleotide polymorphisms, insertions and deletions were identified by Genome Analysis Toolkit. The identified variants in known genes were classified according to the recommended guidelines (Xu et al., 2019). The candidate disease-causing variations found by WES were checked by Sanger sequencing.

\section{Expression plasmid constructs and site-targeted mutagenesis}

The wild-type TBX5 expression plasmid TBX5pcDNA3.1 was constructed as described elsewhere (Zhang et al., 2015). The mutant-type TBX5-pcDNA3.1 was produced via PCR-based site-targeted mutagenesis with a complimentary 
pair of primers and the QuickChange II XL Site-Directed Mutagenesis Kit (Stratagene, La Jolla, CA, USA) according to the manufacturer's protocol. The mutant was selected by $D p n \mathrm{I}$ (NEB, Hitchin, UK) and was fully sequenced to confirm the desired mutation and to exclude any other unwanted sequence variations. The eukaryotic expression vectors GATA4pSSRa and NKX2-5-pEFSA, and the natriuretic peptide precursor A-luciferase (NPPA-luc) reporter vector, which expresses Firefly luciferase, were kind gift from Dr. Ichiro Shiojima, at the Department of Cardiovascular Science and Medicine, Chiba University, Japan. The $\alpha$-myosin heavy chain 6-luciferase (MYH6-luc) reporter plasmid, which expresses Firefly luciferase, was created as described previously (Chen et al., 2017).

\section{Cell culture, plasmid transfection and luciferase analysis}

COS-7 cells (derived from the Cell Bank of the Chinese Academy of Sciences, Shanghai, China) were grown in DMEM supplemented with 10\% fetal bovine serum (Invitrogen, Carlsbad, CA, USA), as well as penicillin (100 U/mL) and streptomycin $(100 \mu \mathrm{g} / \mathrm{mL})$, in an atmosphere with $5 \% \mathrm{CO}_{2}$ at $37{ }^{\circ} \mathrm{C}$. COS-7 cells were seeded in 24 -well plates, at a density of $2 \times 10^{5}$ per cell before transfection. Plasmids were transfected into cells $24 \mathrm{~h}$ after plating with the Lipofectamine 3000 reagent (Invitrogen) according to the product description. To balance transfection efficiency, the internal control plasmid pGL4.75 (Promega), which expresses the Renilla luciferase, was co-transfected. Specifically, COS-7 cells were transiently transfected with empty pcDNA3.1 $(1.0 \mu \mathrm{g})$, or wild-type TBX5-pcDNA3.1 (1.0 $\mu \mathrm{g})$, or mutant TBX5-pcDNA3.1 $(1.0 \mu \mathrm{g})$, or wild-type TBX5-pcDNA3.1 $(0.5 \mu \mathrm{g})$ plus empty pcDNA3.1 $(0.5 \mu \mathrm{g})$, or wild-type TBX5-pcDNA3.1 $(0.5 \mu \mathrm{g})$ plus mutant TBX5-pcDNA3.1 (0.5 $\mu \mathrm{g})$, together with MYH6luc $(1.5 \mu \mathrm{g})$ and pGL4.75 $(0.04 \mu \mathrm{g})$. To analyze the synergistic transactivation, the same amount $(0.6 \mu \mathrm{g})$ of each expression vector (empty pcDNA3.1, wild-type TBX5-pcDNA3.1, mutant TBX5-pcDNA3.1, NKX2-5-pEFSA, GATA4-pSSRa) was used singly or in combination, in the presence of NPPAluc $(1.0 \mu \mathrm{g})$ and pGL4.75 $(0.04 \mu \mathrm{g})$. The transfected cells were cultured for $48 \mathrm{~h}$, and then were harvested and lysed. The Firefly luciferase and Renilla luciferase activities were measured under the GloMax-96 Microplate Luminometer (Promega) by utilizing the Dual-Glo Luciferase Assay System (Promega), following the manufacturer's manual. The activity of the promoter was presented as fold activation (ratio) of Firefly luciferase relative to Renilla luciferase. Each transfection experiment was conducted in triplicate for three times, and the results for promoter activity were given as mean \pm standard deviation (SD) of three experiments in triplicate.

\section{Statistics}

Differences in promoter activities between two groups were compared using the Student's $t$-test, or one-way ANOVA with Tukey's post hoc test, when indicated, with a $p<0.05$ indicating significant difference.

\section{Results}

\section{Baseline characteristics of the study patients}

In this investigation, a total of 178 unrelated cases suffering from CHD and AF (105 males, with a mean age of 33 years at initial diagnosis of AF) were clinically analyzed in contrast to a total of 292 unrelated control people (173 males, with a mean age of 33 years). The included cases had both echocardiograph-documented CHD and electrocardiogramdocumented AF, while the controls had normal echocardiographs and electrocardiograms, with no evidence of cardiac diseases. All the 178 patients had positive family histories of CHD and AF; whereas none of the 292 control individuals had a positive family history of CHD or AF. No study participants had known traditional pathogenic factors for CHD or AF. There was no significant difference between case and control groups in gender, age or ethnicity. The baseline features of the 178 cases affected with CHD and AF are summarized in Table 1.

\section{Detection of a causative TBX5 mutation}

By sequencing the whole coding regions and flanking introns of the $T B X 5$ gene, a heterozygous variation, NM 000192.3: c.577G>T; p.(Gly193*), was detected in one out of the 178 patients affected with CHD and AF, with an allele frequency of $\sim 0.28 \%$ in the patient population. The variation carrier had positive family histories of CHD and $\mathrm{AF}$ as well as bicuspid aortic valve (BAV). Genetic studies of the variation carrier's available family members revealed that the variation co-segregated with ASD and AF as well as $\mathrm{BAV}$, which were transmitted as autosomal dominant traits. In addition, two family members (II-1 and III-1) had also congenital VSD. The sequence chromatograms illustrating the heterozygous $T B X 5$ variation of $\mathrm{c} .577 \mathrm{G}>\mathrm{T}$ and its wildtype control sequence are given in Figure 1A. The schematic diagrams showing the structural domains of wild-type and mutant TBX5 proteins are illustrated in Figure 1B. The pedigree structure of the family with $\mathrm{CHD}$ and AF as well as BAV is shown in Figure 1C. The phenotypic characteristics as well as mutational status for TBX5 of the affected family members are presented in Table 2. The nonsense mutation was absent from 296 control people, and was not found in the 1000 Genomes Project database, the Genome Aggregation Database, or the Single Nucleotide Polymorphism database (accessed on May 6, 2020), indicating its novelty. Besides, similar with previous studies (Al-Qattan and Abou Al-Shaar, 2015; Chen et al., 2017), no more c.577G > T variation was detected in either cases or controls. Thus, the allele frequency of $T B X 5$ variation identified in this study was $1 / 356(0.28 \%)$ in patients and $0 / 584(0 \%)$ in controls.

Additionally, WES analysis of the genomic DNAs from two affected family members (II-4 and III-4) and one unaffected family member (II-3) of the proband who harbored an identified TBX5 mutation was carried out, and an average of 12,973 exonic variants ranging from 11,652 to 14,395 was detected for each family member. A total of 742 exonic variants were shared by both affected subjects, of which 262 were autosomal, heterozygous non-synonymous, nonsense, and splice site variants. After filtered, only the variation 
Table 1 - Demographic and baseline clinical characteristics of the 178 patients with familial congenital heart disease and atrial fibrillation.

\begin{tabular}{lcc}
\hline Variable & $\mathrm{n}$ or mean & $\%$ or range \\
\hline Demographics & 105 & 59 \\
Male & $33 \pm 15$ & $14-57$ \\
Age at initial diagnosis of AF (years) & $45 \pm 9$ & $18-65$ \\
Age at enrollment (years) & & 38 \\
\hline Distribution of different forms of CHD & 68 & 24 \\
\hline ASD & 43 & 14 \\
VSD & 25 & 10 \\
VSD + ASD & 17 & 6 \\
VSD + PDA & 11 & 6 \\
TOF & 10 & 2 \\
ASD + PDA & 4 & \\
TOF + ASD & & 35 \\
\hline Clinical classification of AF & 63 & 26 \\
\hline Paroxysmal & 46 & 22 \\
Persistent & 39 & 17 \\
Longstanding persistent & 30 & 29 \\
Permanent & & 17 \\
\hline Medical history & 51 & 30 \\
\hline History of cardiac surgery for CHD & \\
History of catheter ablation for AF & & \\
\hline
\end{tabular}

Data are given as means with standard deviations, number, or percentage. CHD, congenital heart defect; AF, atrial fibrillation; VSD, ventricular septal defect; ASD, atrial septal defect; PDA, patent ductus arteriosus; TOF, tetralogy of Fallot.

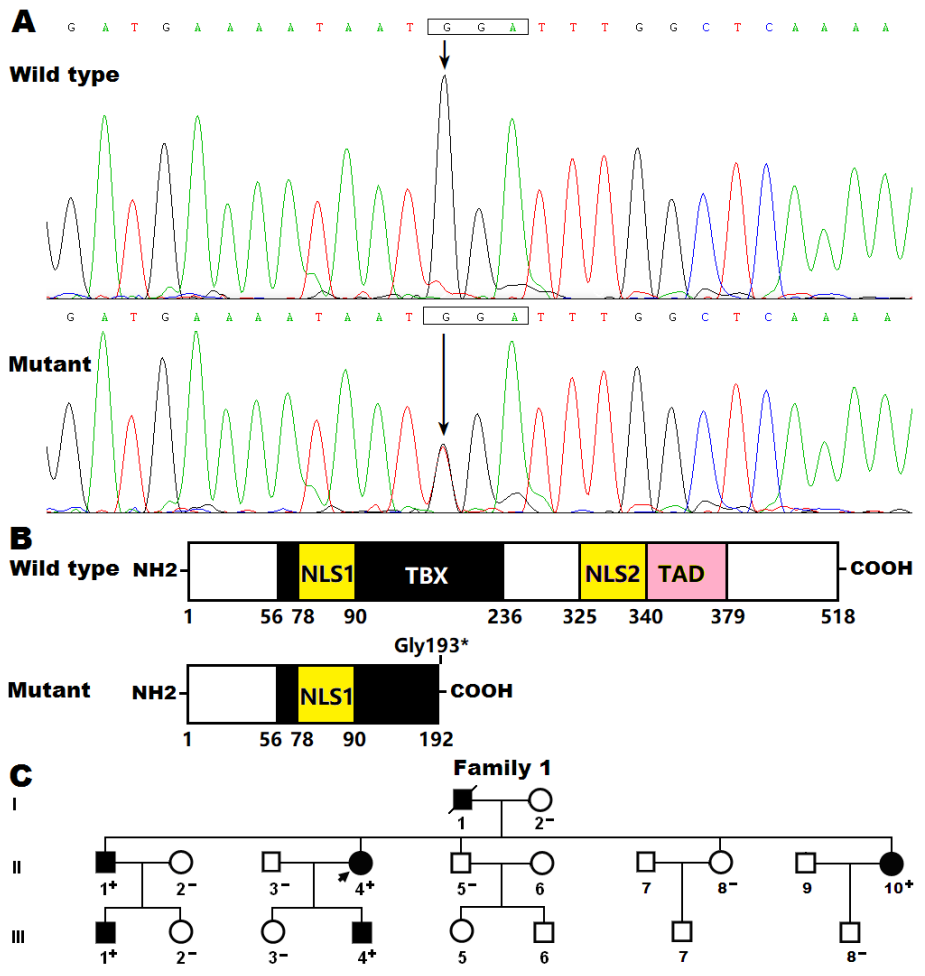

Figure 1 - A new TBX5 mutation responsible for familial heart defect and atrial fibrillation. (A) Sequence chromatograms illustrating the $T B X 5$ heterozygous mutation from the proband (mutant) and its homozygous wild-type control from a healthy individual (wild type). An arrow points to the heterozygous nucleotides of G/T or the homozygous nucleotides of G/G. (B) Schematic drawings showing the structural domains of the TBX5 proteins. NH2, aminoterminus; NLS1, nuclear location signal 1; TBX, T-box; TAD, transcriptional activation domain; NLS2, nuclear location signal 2; COOH, carboxyl-terminus. (C) Pedigree structure of the family suffering from congenital heart defect and atrial fibrillation. Family members are recognized by generations as well as numbers. Circles mean female members; squares, male family member; closed symbols, affected members; open symbols, unaffected members; the symbol with a slash, the deceased member; the arrow beside the closed square, the index patient; “+”, carriers of the TBX5 mutation; “-”, non-carriers. 
Table 2 - Phenotypic features and TBX5 mutation status of the family members with congenital heart defect and atrial fibrillation as well as bicuspid aortic valve.

\begin{tabular}{lccc}
\hline Individual & Gender & Age (years) & Cardiac phenotype \\
\hline I-1 & M & $65^{*}$ & ASD, BAV, AF mutation p.(Gly193*) \\
II-1 & M & 50 & ASD, BAV, AF, VSD \\
II-4 & F & 48 & ASD, BAV, AF \\
II-10 & F & 40 & ASD, BAV, AF \\
III-1 & M & 24 & ASD, BAV, AF, VSD \\
III-4 & M & 22 & ASD, BAV, AF \\
\hline
\end{tabular}

M, male; F, female; ASD, atrial septal defect; BAV, bicuspid aortic valve; AF, atrial fibrillation; VSD, ventricular septal defect; NA, not available; $+/-$, heterozygote.

*Age at death.

c. $577 \mathrm{G}>\mathrm{T}$ in $T B X 5$ was verified by Sanger sequencing and demonstrated to co-segregate with CHD and AF as well as BAV in the family.

\section{No transactivational function of the mutant TBX5 protein}

As shown in Figure 2, the same amount $(1.0 \mu \mathrm{g})$ of wildtype and Gly193*-mutant TBX5 plasmids transcriptionally activated the MYH6 promoter by $\sim 12$ fold and $\sim 1$ fold, respectively (comparison between wild type and mutant: $t=$ $8.07389, p=0.00128$ ). When half the amount of wild-type and Gly193*-mutant TBX5 plasmids (each $0.5 \mu \mathrm{g}$ ) was used, the resultant transcriptional activity was $\sim 6$-fold (comparison between wild type plus empty plasmid and wild type plus mutant: $t=3.91627, p=0.01730)$.

\section{No synergistic effect between mutant TBX5 and NKX2-5 as well as GATA4}

As shown in Figure 3, wild-type and Gly193*-mutant TBX5 activated the NPPA promoter by $\sim 7$ fold and $\sim 1$ fold, respectively (comparison between wild type and mutant: $t=$ 9.24975, $p=0.00076$ ). In combination with wild-type NKX25, wild-type and Gly193*-mutant TBX5 activated the NPPA promoter by $\sim 30$ fold and $\sim 5$ fold, respectively (comparison between wild type and mutant: $t=9.36360, p=0.00072$ ); while together with wild-type GATA4, wild-type and Gly193*. mutant TBX5 transcriptionally activated the NPPA promoter by $\sim 22$ fold and $\sim 4$ fold, respectively (comparison between wild type and mutant: $t=9.51139, p=0.00068$ ).

\section{Discussion}

In the current investigation, a novel heterozygous TBX5 variation, NM_000192.3: c.577G > T; p.(Gly193*), was discovered in a family with CHD and AF as well as BAV. The variation was absent in the 584 reference chromosomes as well as in such population databases as the 1000 Genomes Project database, the Genome Aggregation Database, and the Single Nucleotide Polymorphism database. Functional explorations showed that Gly193*-mutant TBX5 lost transcriptional activity on the MYH6 and NPPA promoters. Moreover, the mutation disrupted the synergistic transcriptional effect between TBX5 and GATA4 as well as NKX2-5. Additionally, WES analysis showed no other genes contributing to the diseases of the family. These observational results indicate that the pathogenic variation in the TBX5 gene predisposes to $\mathrm{CHD}$ and $\mathrm{AF}$ as well as BAV.

In humans, $T B X 5$ is located on chromosome $12 \mathrm{q} 24.1$, which encodes a 518-amino acid protein. The TBX5 protein harbors four functionally important domains, including a T-box domain (TBX; amino acids 56-236), which functions to bind target DNAs and interact with other proteins; a transcriptional activation domain (TAD; amino acids 339-379), which is responsible for transactivation of target genes; and two nuclear localization signals (NLS) including NLS1 (amino acids 7890) and NLS2 (amino acids 325-340), which were essential for nuclear localization (Steimle and Moskowitz1, 2017). Previous studies have corroborated that TBX5 is highly expressed in the hearts of humans and vertebrates, encompassing the endocardium, myocardium, and epicardium of embryonic and adult hearts, and its expression is much higher in atria than in ventricles during embryogenesis, where it plays a key role in cardiovascular morphogenesis and postnatal heart remodeling (Steimle and Moskowitz1, 2017). Recent research has validated that TBX5 transcriptionally regulates expression of many target genes, including NPPA, GJA5, MYH6 and $S C N 5 A$, separately or together with GATA4, GATA6, NKX2-5, MEF2C and TBX20 (Steimle and Moskowitz1, 2017), and variations in TBX5 and its target genes as well as cooperative partners have been reported to result in CHD and/or AF in humans (Postma et al., 2008; Mahida, 2014; Guo et al., 2016; Ma et al., 2016; Wang et al., 2016; Li and Yang, 2017; Campbell and Wehrens, 2018). In the current investigation, the pathogenic variation detected in patients with familial CHD and AF as well as BAV was predicted to produce a truncating TBX5 protein with most functional domains lost, and functional explorations revealed that the mutant TBX5 protein failed to transcriptionally activate target genes. Moreover, the pathogenic variation ablated the synergistic transactivation between TBX5 and NKX2-5 as well as GATA4. These data indicate that $T B X 5$ haploinsufficiency is a molecular mechanism of CHD and AF as well as BAV in a subset of patients.

It might be ascribed to the aberrant cardiovascular genesis that TBX5 deficiency contributes to CHD and AF. In mice, TBX5 is abundantly expressed in entire cardiac crescent, heart tube, left ventricle, vena cavae, common 


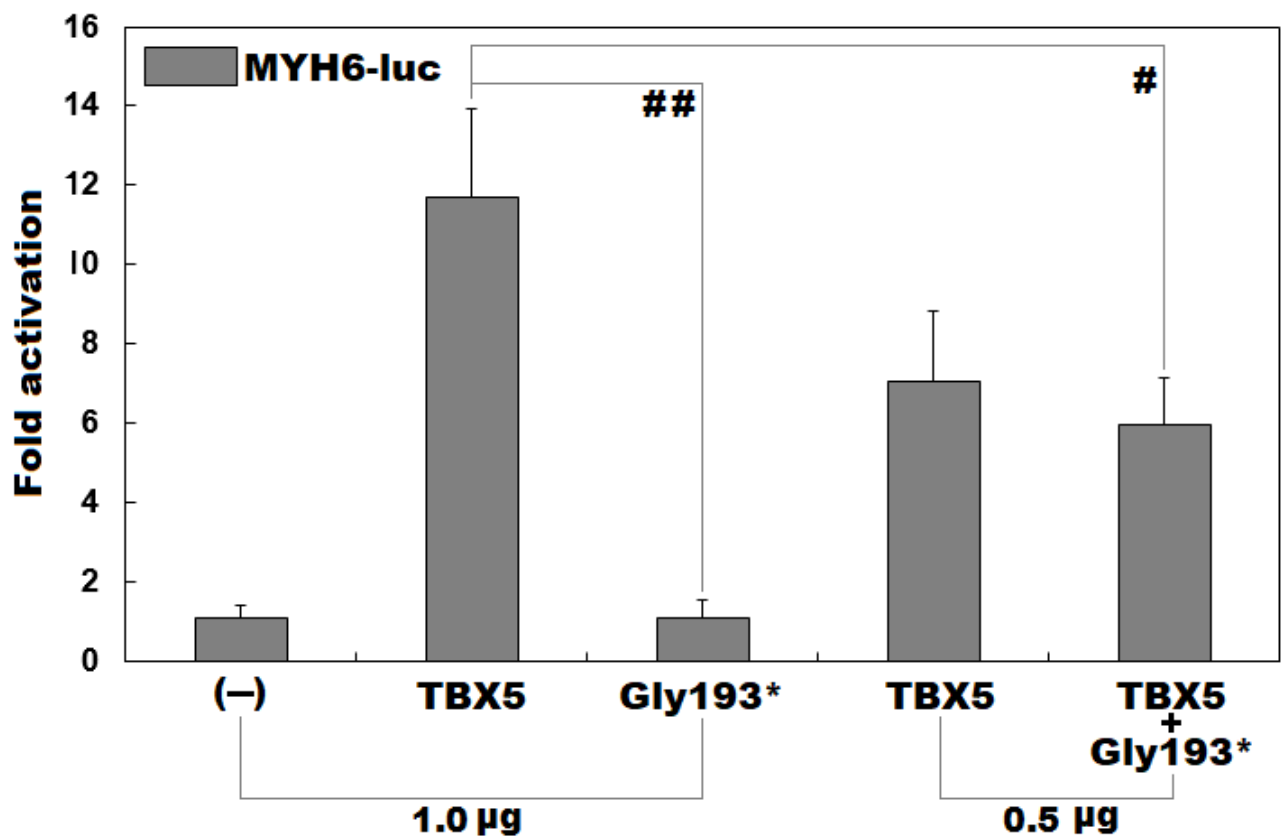

Figure 2 - Functional failure of TBX 5 caused by the mutation. Activation of $\alpha$-myosin heavy chain 6 promoter-driven luciferase in cultured COS-7 cells by wild-type or Gly193*-mutant TBX5, singly or together, revealed that the Gly193*-mutant TBX5 protein had no transcriptional activity. Transfection experiments for each plasmid were carried out in triplicates and the results are expressed as means with standard deviations. Here \#\# and \# indicate $p<0.01$ and $p<0.02$, respectively, in comparison with wild-type TBX5.

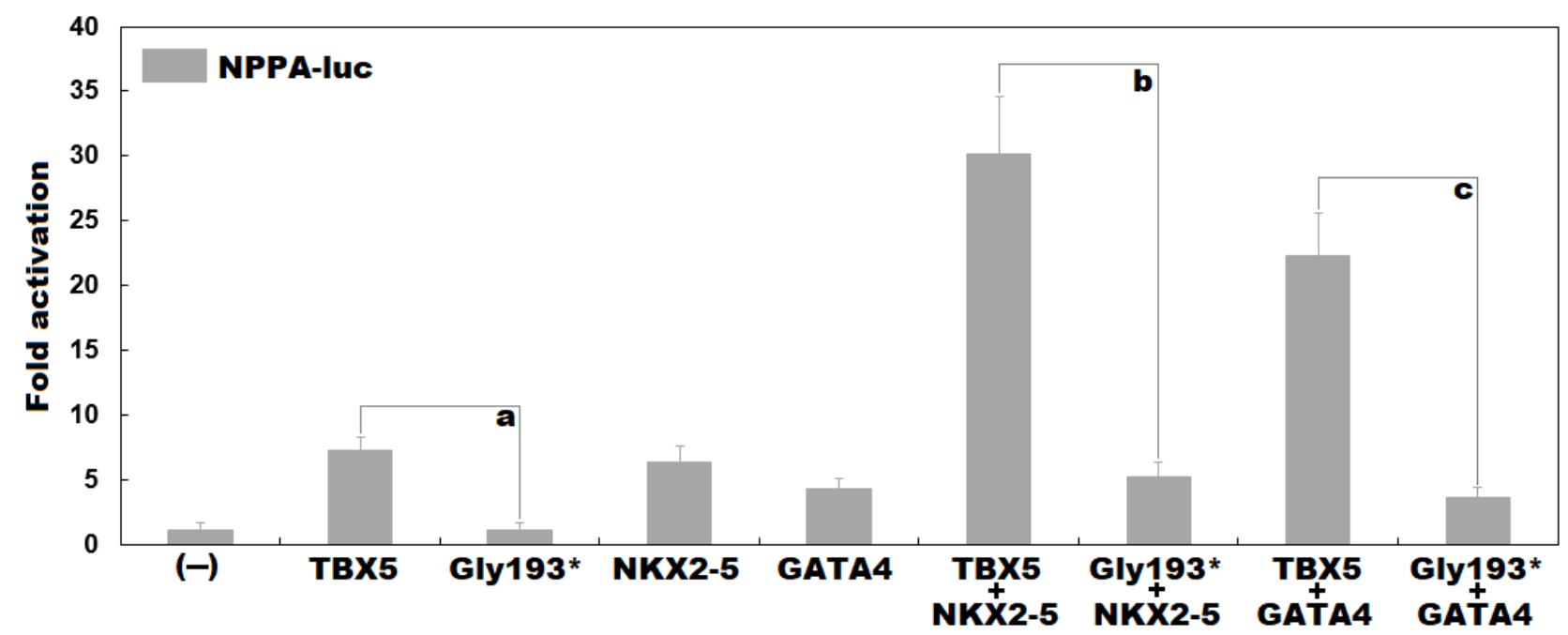

Figure 3 - Disrupted synergistic transactivation between mutant TBX5 and NKX2-5 as well as GATA4. The synergistic transactivation of the promoter of natriuretic peptide precursor A in cultured cells by TBX 5 and NKX2-5 as well as GATA4 was ablated by the Gly $193 *$ mutation. Transfection experiments for each plasmid were done in triplicates, with means and standard deviations shown. Here the symbols a, $\mathrm{b}$ and $\mathrm{c}$ all indicate $p<0.001$, in comparison with their wild-type counterparts.

atrium, and cardiac central conduction system, encompassing atrioventricular bundle and bundle branches (Bruneau et al., 1999; Moskowitz et al., 2004). Homozygous deletion of Tbx5 led to murine embryonic death because of failure to undergo cardiac looping as well as left ventricular and sinoatrial hypoplasia; while heterozygous Tbx5-bull mice showed ASD, VSD, left ventricular hypoplasia, endocardial cushion defect, and conduction system anomalies, encompassing atrioventricular conduction blocks and bundle branch blocks (Bruneau et al., 1999; Bruneau et al., 2001; Moskowitz et al., 2004). In addition, in murine hearts Tbx 5 haploinsufficiency also markedly reduced the transcription of multiple target genes, including Nppa and Cx40 (Bruneau et al., 2001).
Moreover, adult-restricted $T b x 5$-mutant mice demonstrated spontaneous AF, and in Tbx5-deficient atrial cardiomyocytes, action potential abnormalities occurred due to a decreased SERCA2-mediated sarcoplasmic reticulum calcium uptake (Dai et al., 2019). In human beings, TBX5 is highly expressed in embryonic and postnatal hearts (Hatcher et al., 2000), and a number of $T B X 5$ loss- or gain-of-function mutations have been causally linked to HOS, including CHD and AF as well as cardiac block (Al-Qattan and Abou Al-Shaar, 2015). Taken collectively, these findings suggest that genetically defective $T B X 5$ enhances the susceptibility to CHD and AF in humans, and underscore that TBX5 dosage must be precisely regulated to avoid heart disorders. 
Notably, previous studies have causally linked $T B X 5$ variations to various cardiovascular malformations, including ASD, VSD, atrioventricular septal defect, pulmonary stenosis, hypoplastic left ventricle, mitral valve anomaly (Gharibeh et al., 2018). In the current investigation, the affected family members had also BAV, in addition to ASD, VSD and AF, thus expanding the phenotypic spectrum linked to mutant $T B X 5$. Given that loss-of-function mutations in multiple transcriptional partners of TBX5 (Balistreri et al., 2019), encompassing GATA6 (Gharibeh et al., 2018; Xu et al., 2018), GATA4 (Yang et al., 2017; Li et al., 2018c), GATA5 (Padang et al., 2012; Bonachea et al., 2014; Shi et al., 2014), NKX2-5 (Qu et al., 2014), and TBX20 (Luyckx et al., 2019), have been related to BAV, it is very likely that mutated TBX 5 contributes to BAV by reducing expression of the target genes related to BAV morphogenesis in synergy with these partners.

\section{Conclusions}

This investigation causally links TBX5 loss-of-function mutation to $\mathrm{CHD}, \mathrm{AF}$ and BAV for the first time, which highlights the key role of abnormal cardiovascular development in the pathogenesis of $\mathrm{CHD}, \mathrm{AF}$ and $\mathrm{BAV}$, implying potential implications for individualized prophylaxis and management of patients with $\mathrm{CHD}$ and $\mathrm{AF}$ as well as BAV.

\section{Acknowledgments}

The authors thank the study participants for their dedication to this investigation. This work was financially supported by grants from the National Natural Science Foundation of China (81670305, 81600228, 81470372), the Science and Technology Support Project of Medical Guidance, Shanghai, China (19411971900), the Natural Science Foundation of Shanghai, China (18ZR1423400), the Program of Health and Family Planning Commission of Shanghai, China (201740064 and 20154Y0026), and the Key Project of Shanghai Fifth People's Hospital, Fudan University, China (2018WYZD05).

\section{Conflict of Interest}

The authors declare that they have no conflict of interest.

\section{Author Contributions}

WFJ, YJX, SHW, YQY conceived and designed the study. WFJ, YJX, CMZ, XHW, XBQ, XL, SHW, YQY analyzed and interpreted the patient data. WFJ, YJX, CMZ, SHW, YQY performed the experiments. WFJ and YQY wrote the manuscript. All authors have read and approved the final version.

\section{References}

Abassi H, Gavotto A, Picot MC, Bertet H, Matecki S, Guillaumont S, Moniotte S, Auquier P, Moreau J and Amedro P (2019) Impaired pulmonary function and its association with clinical outcomes, exercise capacity and quality of life in children with congenital heart disease. Int J Cardiol 285:86-92.

Al-Qattan MM and Abou Al-Shaar H (2015) Molecular basis of the clinical features of Holt-Oram syndrome resulting from missense and extended protein mutations of the $T B X 5$ gene as well as TBX5 intragenic duplications. Gene 560:129-136.
Alankarage D, Ip E, Szot JO, Munro J, Blue GM, Harrison K, Cuny H, Enriquez A, Troup M, Humphreys DT et al. (2019) Identification of clinically actionable variants from genome sequencing of families with congenital heart disease. Genet Med 21:1111-1120.

Amedro P, Bajolle F, Bertet H, Cheurfi R, Lasne D, Nogue E, Auquier P, Picot MC and Bonnet D (2018) Quality of life in children participating in a non-selective INR self-monitoring VKAeducation programme. Arch Cardiovasc Dis 111:180-188.

Amedro P, Gavotto A, Legendre A, Lavastre K, Bredy C, De La Villeon G, Matecki S, Vandenberghe D, Ladeveze M, Bajolle F et al. (2019) Impact of a centre and home-based cardiac rehabilitation program on the quality of life of teenagers and young adults with congenital heart disease: The QUALIREHAB study rationale, design and methods. Int J Cardiol 283:112-118.

Balistreri CR, Forte M, Greco E, Paneni F, Cavarretta E, Frati G and Sciarretta S (2019) An overview of the molecular mechanisms underlying development and progression of bicuspid aortic valve disease. J Mol Cell Cardiol 132:146-153.

Barry OM, Gauvreau K, Rhodes J, Reichman JR, Bourette L, Curran T, O'Neill J, Pymm JL and Alexander ME (2018) Incidence and predictors of clinically important and dangerous arrhythmias during exercise tests in pediatric and congenital heart disease patients. JACC Clin Electrophysiol 4:1319-1327.

Bashamboo A, Eozenou C, Jorgensen A, Bignon-Topalovic J, Siffroi JP, Hyon C, Tar A, Nagy P, Sólyom J, Halász Z et al. (2018) Loss of function of the nuclear receptor NR2F2, encoding COUP-TF2, causes testis development and cardiac defects in 46,XX children. Am J Hum Genet 102:487-493.

Benjamin EJ, Muntner P, Alonso A, Bittencourt MS, Callaway CW, Carson AP, Chamberlain AM, Chang AR, Cheng S, Das SR et al. (2019) Heart disease and stroke statistics-2019 update: A report from the American Heart Association. Circulation 139:e56-e528.

Bokma JP, Zegstroo I, Kuijpers JM, Konings TC, van Kimmenade RRJ, van Melle JP, Kiès P, Mulder BJM and Bouma BJ (2018) Factors associated with coronary artery disease and stroke in adults with congenital heart disease. Heart 104:574-580.

Bonachea EM, Chang SW, Zender G, LaHaye S, Fitzgerald-Butt S, McBride KL and Garg V (2014) Rare GATA5 sequence variants identified in individuals with bicuspid aortic valve. Pediatr Res 76:211-216.

Boukovala M, Müller J, Ewert P and Hager A (2019) Effects of congenital heart disease treatment on quality of life. Am J Cardiol 123:1163-1168.

Bouma BJ and Mulder BJ (2017) Changing landscape of congenital heart disease. Circ Res 120:908-922.

Brida M and Gatzoulis MA (2018) Pulmonary arterial hypertension in adult congenital heart disease. Heart 104:1568-1574.

Bruneau BG, Logan M, Davis N, Levi T, Tabin CJ, Seidman JG and Seidman CE (1999) Chamber-specific cardiac expression of Tbx 5 and heart defects in Holt-Oram syndrome. Dev Biol 211:100-108.

Bruneau BG, Nemer G, Schmitt JP, Charron F, Robitaille L, Caron S, Conner DA, Gessler M, Nemer M, Seidman CE et al. (2001) A murine model of Holt-Oram syndrome defines roles of the T-box transcription factor Tbx 5 in cardiogenesis and disease. Cell 106:709-721.

Cahill TJ, Jewell PD, Denne L, Franklin RC, Frigiola A, Orchard E and Prendergast BD (2019) Contemporary epidemiology of infective endocarditis in patients with congenital heart disease: a UK prospective study. Am Heart J 215:70-77.

Campbell HM and Wehrens XHT (2018) Genetics of atrial fibrillation: an update. Curr Opin Cardiol 33:304-310. 
Cantù C, Felker A, Zimmerli D, Prummel KD, Cabello EM, Chiavacci E, Méndez-Acevedo KM, Kirchgeorg L, Burger S, Ripoll J et al. (2018) Mutations in Bcl9 and Pygo genes cause congenital heart defects by tissue-specific perturbation of Wnt/ $/$-catenin signaling. Genes Dev 32:1443-1458.

Chan J, Collins RT II, Hall M and John A (2019) Resource utilization among adult congenital heart failure admissions in pediatric hospitals. Am J Cardiol 123:839-846.

Chen HX, Zhang X, Hou HT, Wang J, Yang Q, Wang XL and He $\mathrm{GW}$ (2017) Identification of a novel and functional mutation in the TBX 5 gene in a patient by screening from 354 patients with isolated ventricular septal defect. Eur J Med Genet 60:385-390.

Dai W, Laforest B, Tyan L, Shen KM, Nadadur RD, Alvarado FJ, Mazurek SR, Lazarevic S, Gadek M, Wang Y et al. (2019) A calcium transport mechanism for atrial fibrillation in Tbx5mutant mice. Elife 8:e41814

Dimopoulos K, Condliffe R, Tulloh RMR, Clift P, Alonso-Gonzalez R, Bedair R, Chung NAY, Coghlan G, Fitzsimmons S, Frigiola A et al. (2018) Echocardiographic screening for pulmonary hypertension in congenital heart disease: JACC review topic of the week. J Am Coll Cardiol 72:2778-2788.

Faucherre A, Moha Ou Maati H, Nasr N, Pinard A, Theron A, Odelin G, Desvignes JP, Salgado D, Collod-Béroud G, Avierinos JF et al. (2020) Piezol is required for outflow tract and aortic valve development. J Mol Cell Cardiol 143:51-62.

Fuchs SR, Smith AH, Van Driest SL, Crum KF, Edwards TL and Kannankeril PJ (2019) Incidence and effect of early postoperative ventricular arrhythmias after congenital heart surgery. Heart Rhythm 16:710-716.

Gao X, Zheng P, Yang L, Luo H, Zhang C, Qiu Y, Huang G, Sheng W, Ma X and Lu C (2019) Association of functional variant in GDF1 promoter with risk of congenital heart disease and its regulation by Nkx2.5. Clin Sci (Lond) 133:1281-1295.

Gharibeh L, Komati H, Bossé Y, Boodhwani M, Heydarpour M, Fortier M, Hassanzadeh R, Ngu J, Mathieu P, Body S et al. (2018) GATA6 regulates aortic valve remodeling, and its haploinsufficiency leads to right-left type bicuspid aortic valve. Circulation 138:1025-1038.

Giang KW, Mandalenakis Z, Dellborg M, Lappas G, Eriksson P, Hansson PO and Rosengren A (2018) Long-term risk of hemorrhagic stroke in young patients with congenital heart disease. Stroke 49:1155-1162.

Gilbert K, Forsch N, Hegde S, Mauger C, Omens JH, Perry JC, Pontré B, Suinesiaputra A, Young AA and McCulloch AD (2018) Atlas-based computational analysis of heart shape and function in congenital heart disease. J Cardiovasc Transl Res 11:123-132.

Gist KM, Kwiatkowski DM and Cooper DS (2018) Acute kidney injury in congenital heart disease. Curr Opin Cardiol 33:101107.

Guo DF, Li RG, Yuan F, Shi HY, Hou XM, Qu XK, Xu YJ, Zhang M, Liu X, Jiang JQ et al. (2016) TBX5 loss-of-function mutation contributes to atrial fibrillation and atypical HoltOram syndrome. Mol Med Rep 13:4349-4356.

Hatcher CJ, Goldstein MM, Mah CS, Delia CS and Basson CT (2000) Identification and localization of TBX5 transcription factor during human cardiac morphogenesis. Dev Dyn 219:90-95.

Hernández-Madrid A, Paul T, Abrams D, Aziz PF, Blom NA, Chen J, Chessa M, Combes N, Dagres N, Diller G et al. (2018) Arrhythmias in congenital heart disease: a position paper of the European Heart Rhythm Association (EHRA), Association for European Paediatric and Congenital Cardiology (AEPC), and the European Society of Cardiology (ESC) Working Group on Grown-up Congenital heart disease, endorsed by HRS, PACES, APHRS, and SOLAECE. Europace 20:1719-1753.
January CT, Wann LS, Alpert JS, Calkins H, Cigarroa JE, Cleveland JC Jr, Conti JB, Ellinor PT, Ezekowitz MD, Field ME et al. (2014) 2014 AHA/ACC/HRS guideline for the management of patients with atrial fibrillation: a report of the American College of Cardiology/American Heart Association Task Force on Practice Guidelines and the Heart Rhythm Society. J Am Coll Cardiol 64:e1-e76.

Jaouadi A, Tabebi M, Abdelhedi F, Abid D, Kamoun F, Chabchoub I, Maatoug S, Doukali H, Belghuith N, Ksentini MA et al. (2018) A novel TBX1 missense mutation in patients with syndromic congenital heart defects. Biochem Biophys Res Commun 499:563-569.

Jortveit J, Klcovansky J, Eskedal L, Birkeland S, Døhlen G and Holmstrøm H (2018) Endocarditis in children and adolescents with congenital heart defects: a Norwegian nationwide registerbased cohort study. Arch Dis Child 103:670-674.

Kaemmerer H, Apitz C, Brockmeier K, Eicken A, Gorenflo M, Hager A, de Haan F, Huntgeburth M, Kozlik-Feldmann RG, Miera O et al. (2018) Pulmonary hypertension in adults with congenital heart disease: updated recommendations from the Cologne Consensus Conference 2018. Int J Cardiol 272S:79-88.

Kalayinia S, Maleki M, Mahdavi M and Mahdieh N (2020) A novel de novo dominant mutation of NOTCH1 gene in an Iranian family with non-syndromic congenital heart disease. J Clin Lab Anal 34:e23147.

Kalayinia S, Maleki M, Rokni-Zadeh H, Changi-Ashtiani M, Ahangar H, Biglari A, Shahani T and Mahdieh N (2019) GATA4 screening in Iranian patients of various ethnicities affected with congenital heart disease: co-occurrence of a novel de novo translocation $(5 ; 7)$ and a likely pathogenic heterozygous GATA4 mutation in a family with autosomal dominant congenital heart disease. J Clin Lab Anal 33:e22923.

Khanna AD, Duca LM, Kay JD, Shore J, Kelly SL and Crume T (2019) Prevalence of mental illness in adolescents and adults with congenital heart disease from the Colorado Congenital Heart Defect Surveillance System. Am J Cardiol 124:618-626.

Labombarda F, Hamilton R, Shohoudi A, Aboulhosn J, Broberg CS, Chaix MA, Cohen S, Cook S, Dore A, Fernandes SM et al. (2017) Increasing prevalence of atrial fibrillation and permanent atrial arrhythmias in congenital heart disease. $\mathrm{J}$ Am Coll Cardiol 70:857-865.

Lal S, Kotchetkova I, Cao J, Jackson D, Cordina R and Celermajer DS (2018) Heart failure admissions and poor subsequent outcomes in adults with congenital heart disease. Eur J Heart Fail 20:812-815.

Li B, Yu L, Liu D, Yang X, Zheng Y, Gui Y and Wang H (2018a) MIB1 mutations reduce Notch signaling activation and contribute to congenital heart disease. Clin Sci (Lond) 132:2483-2491.

Li N, Wang ZS, Wang XH, Xu YJ, Qiao Q, Li XM, Di RM, Guo XJ, Li RG, Zhang M et al. (2018b) A SHOX2 loss-of-function mutation underlying familial atrial fibrillation. Int J Med Sci 15:1564-1572.

Li RG, Xu YJ, Wang J, Liu XY, Yuan F, Huang RT, Xue S, Li L, Liu H, Li YJ et al. (2018c) GATA4 loss-of-function mutation and the congenitally bicuspid aortic valve. Am J Cardiol 121:469-474.

Li YJ and Yang YQ (2017) An update on the molecular diagnosis of congenital heart disease: focus on loss-of-function mutations. Expert Rev Mol Diagn 17:393-401.

Lombardo RC, Porollo A, Cnota JF and Hopkin RJ (2018) Congenital heart disease and aortic arch variants associated with mutation in PHOX2B. Genet Med 20:1538-1543.

Lui GK, Saidi A, Bhatt AB, Burchill LJ, Deen JF, Earing MG, Gewitz M, Ginns J, Kay JD, Kim YY et al. (2017) Diagnosis and management of noncardiac complications in adults with congenital heart disease: A scientific statement from the American Heart Association. Circulation 136:e348-e392. 
Luyckx I, Kumar AA, Reyniers E, Dekeyser E, Vanderstraeten K, Vandeweyer G, Wünnemann F, Preuss C, Mazzella JM, Goudot G et al. (2019) Copy number variation analysis in bicuspid aortic valve-related aortopathy identifies TBX20 as a contributing gene. Eur J Hum Genet 27:1033-1043.

Lynge TH, Jeppesen AG, Winkel BG, Glinge C, Schmidt MR, Søndergaard L, Risgaard B and Tfelt-Hansen J (2018) Nationwide study of sudden cardiac death in people with congenital heart defects aged 0 to 35 years. Circ Arrhythm Electrophysiol 11:e005757.

Ma JF, Yang F, Mahida SN, Zhao L, Chen X, Zhang ML, Sun Z, Yao Y, Zhang YX, Zheng GY et al. (2016) TBX5 mutations contribute to early-onset atrial fibrillation in Chinese and Caucasians. Cardiovasc Res 109:442-450.

Ma L, Wang J, Li L, Qiao Q, Di RM, Li XM, Xu YJ, Zhang M, Li RG, Qiu XB et al. (2019) ISL1 loss-of-function mutation contributes to congenital heart defects. Heart Vessels 34:658-668.

Mahida S (2014) Transcription factors and atrial fibrillation. Cardiovasc Res 101:194-202.

Manheimer KB, Richter F, Edelmann LJ, D’Souza SL, Shi L, Shen Y, Homsy J, Boskovski MT, Tai AC, Gorham J et al. (2018) Robust identification of mosaic variants in congenital heart disease. Hum Genet 137:183-193.

Moore B, Yu C, Kotchetkova I, Cordina R and Celermajer DS (2018) Incidence and clinical characteristics of sudden cardiac death in adult congenital heart disease. Int J Cardiol 254:101-106.

Moskowitz IP, Pizard A, Patel VV, Bruneau BG, Kim JB, Kupershmidt S, Roden D, Berul CI, Seidman CE and Seidman JG (2004) The T-Box transcription factor Tbx 5 is required for the patterning and maturation of the murine cardiac conduction system. Development 131:4107-4116.

Müller J, Ewert P and Hager A (2018) Number of thoracotomies predicts impairment in lung function and exercise capacity in patients with congenital heart disease. J Cardiol 71:88-92.

Oliveira-Brancati CIF, Ferrarese VCC, Costa AR and Fett-Conte AC (2020) Birth defects in Brazil: Outcomes of a population-based study. Genet Mol Biol 43:e20180186.

Padang R, Bagnall RD, Richmond DR, Bannon PG and Semsarian C (2012) Rare non-synonymous variations in the transcriptional activation domains of GATA5 in bicuspid aortic valve disease. J Mol Cell Cardiol 53:277-281.

Pascall E and Tulloh RM (2018) Pulmonary hypertension in congenital heart disease. Future Cardiol 14:343-353.

Patel SS and Burns TL (2013) Nongenetic risk factors and congenital heart defects. Pediatr Cardiol 34:1535-1555.

Pedersen MGB, Olsen MS, Schmidt M, Johnsen SP, Learn C, Laursen HB and Madsen NL (2019) Ischemic stroke in adults with congenital heart disease: a population-based cohort study. J Am Heart Assoc 8:e011870.

Peyvandi S, Chau V, Guo T, Xu D, Glass HC, Synnes A, Poskitt K, Barkovich AJ, Miller SP and McQuillen PS (2018) Neonatal brain injury and timing of neurodevelopmental assessment in patients with congenital heart disease. J Am Coll Cardiol 71:1986-1996.

Peyvandi S, Latal B, Miller SP and McQuillen PS (2019) The neonatal brain in critical congenital heart disease: Insights and future directions. Neuroimage 185:776-782.

Pierpont ME, Brueckner M, Chung WK, Garg V, Lacro RV, McGuire AL, Mital S, Priest JR, Pu WT, Roberts A et al. (2018) Genetic basis for congenital heart disease: revisited: A scientific statement from the American Heart Association. Circulation 138:e653-e711.

Postma AV, van de Meerakker JB, Mathijssen IB, Barnett P, Christoffels VM, Ilgun A, Lam J, Wilde AA, Lekanne Deprez RH and Moorman AF (2008) A gain-of-function TBX5 mutation is associated with atypical Holt-Oram syndrome and paroxysmal atrial fibrillation. Circ Res 102:1433-1442.
Qiao XH, Wang Q, Wang J, Liu XY, Xu YJ, Huang RT, Xue S, Li YJ, Zhang M, Qu XK et al. (2018) A novel NR2F2 loss-offunction mutation predisposes to congenital heart defect. Eur J Med Genet 61:197-203.

Qu XK, Qiu XB, Yuan F, Wang J, Zhao CM, Liu XY, Zhang XL, Li RG, Xu YJ, Hou XM et al. (2014) A novel NKX2.5 loss-offunction mutation associated with congenital bicuspid aortic valve. Am J Cardiol 114:1891-1895.

Razmara E and Garshasbi M (2018) Whole-exome sequencing identifies R1279X of MYH6 gene to be associated with congenital heart disease. BMC Cardiovasc Disord 18:137.

Sabanayagam A, Cavus O, Williams J and Bradley E (2018) Management of heart failure in adult congenital heart disease. Heart Fail Clin 14:569-577.

Shabana NA, Shahid SU and Irfan U (2020) Genetic contribution to congenital heart disease (CHD). Pediatr Cardiol 41:12-23.

Shi LM, Tao JW, Qiu XB, Wang J, Yuan F, Xu L, Liu H, Li RG, Xu YJ, Wang Q et al. (2014) GATA5 loss-of-function mutations associated with congenital bicuspid aortic valve. Int J Mol Med 33:1219-1226.

Smith MP, Müller J, Neidenbach R, Ewert P and Hager A (2019) Better lung function with increased hand grip strength, as well as maximum oxygen uptake, in congenital heart disease across the lifespan. Eur J Prev Cardiol 26:492-501.

Spector LG, Menk JS, Knight JH, McCracken C, Thomas AS, Vinocur JM, Oster ME, St Louis JD, Moller JH and Kochilas L (2018) Trends in long-term mortality after congenital heart surgery. J Am Coll Cardiol 71:2434-2446.

Steimle JD and Moskowitz1 IP (2017) TBX5: A key regulator of heart development. Curr Top Dev Biol 122:195-221.

Stephen J, Maddirevula S, Nampoothiri S, Burke JD, Herzog M, Shukla A, Steindl K, Eskin A, Patil SJ, Joset P et al. (2018) Bi-allelic TMEM94 truncating variants are associated with neurodevelopmental delay, congenital heart defects, and distinct facial dysmorphism. Am J Hum Genet 103:948-967.

Trusty PM, Slesnick TC, Wei ZA, Rossignac J, Kanter KR, Fogel MA and Yoganathan AP (2018) Fontan surgical planning: previous accomplishments, current challenges, and future directions. J Cardiovasc Transl Res 11:133-144.

Tutarel O, Alonso-Gonzalez R, Montanaro C, Schiff R, Uribarri A, Kempny A, Grübler MR, Uebing A, Swan L, Diller GP et al. (2018) Infective endocarditis in adults with congenital heart disease remains a lethal disease. Heart 104:161-165.

Wang J, Abhinav P, Xu YJ, Li RG, Zhang M, Qiu XB, Di RM, Qiao Q, Li XM, Huang RT et al. (2019) NR2F2 loss-of-function mutation is responsible for congenital bicuspid aortic valve. Int J Mol Med 43:1839-1846.

Wang Z, Song HM, Wang F, Zhao CM, Huang RT, Xue S, Li RG, Qiu XB, Xu YJ, Liu XY et al. (2019) A new ISL1 loss-offunction mutation predisposes to congenital double outlet right ventricle. Int Heart J 60:1113-1122.

Wang ZC, Ji WH, Ruan CW, Liu XY, Qiu XB, Yuan F, Li RG, Xu YJ, Liu X, Huang RT et al. (2016) Prevalence and spectrum of TBX5 mutation in patients with lone atrial fibrillation. Int J Med Sci 13:60-67.

Watkins WS, Hernandez EJ, Wesolowski S, Bisgrove BW, Sunderland RT, Lin E, Lemmon G, Demarest BL, Miller TA, Bernstein D et al. (2019) De novo and recessive forms of congenital heart disease have distinct genetic and phenotypic landscapes. Nat Commun 10:4722.

Xu YJ, Di RM, Qiao Q, Li XM, Huang RT, Xue S, Liu XY, Wang J and Yang YQ (2018) GATA6 loss-of-function mutation contributes to congenital bicuspid aortic valve. Gene 663:115-120.

Xu YJ, Wang ZS, Yang CX, Di RM, Qiao Q, Li XM, Gu JN, Guo XJ and Yang YQ (2019) Identification and functional characterization of an ISL1 mutation predisposing to dilated cardiomyopathy. J Cardiovasc Transl Res 12:257-267. 
Yang B, Zhou W, Jiao J, Nielsen JB, Mathis MR, Heydarpour M, Lettre G, Folkersen L, Prakash S, Schurmann C et al. (2017) Protein-altering and regulatory genetic variants near GATA4 implicated in bicuspid aortic valve. Nat Commun 8:15481.

$\mathrm{Yu}$ C, Moore BM, Kotchetkova I, Cordina RL and Celermajer DS (2018) Causes of death in a contemporary adult congenital heart disease cohort. Heart 104:1678-1682.

Yu Z, Tang PL, Wang J, Bao S, Shieh JT, Leung AW, Zhang Z, Gao F, Wong SY, Hui AL et al. (2018) Mutations in Hnrnpal cause congenital heart defects. JCI Insight 3:98555.

Zhang XL, Qiu XB, Yuan F, Wang J, Zhao CM, Li RG, Xu L, Xu YJ, Shi HY, Hou XM et al. (2015) TBX5 loss-of-function mutation contributes to familial dilated cardiomyopathy. Biochem Biophys Res Commun 459:166-171.

Zhao Y, Diacou A, Johnston HR, Musfee FI, McDonald-McGinn DM, McGinn D, Crowley TB, Repetto GM, Swillen A, Breckpot J et al. (2020) Complete sequence of the 22q11.2 allele in 1,053 subjects with $22 \mathrm{q} 11.2$ deletion syndrome reveals modifiers of conotruncal heart defects. Am J Hum Genet 106:26-40.
Zhu MJ, Ma XY, Ding PC, Tang HF, Peng R, Lu L, Li PQ, Qiao B, Yang XY, Zheng YF et al. (2019) Novel mutations of AXIN2 identified in a Chinese congenital heart disease cohort. J Hum Genet 64:427-435.

\section{Internet Resources}

The 1000 Genomes Project database, http://www.1000genomes. org (May 6, 2020).

The Genome Aggregation Database, https://gnomad.broadinstitute. org (May 6, 2020).

The Single Nucleotide Polymorphism database, http://www.ncbi. nlm.nih.gov/snp (May 6, 2020).

Associate Editor: Mara H. Hutz

License information: This is an open-access article distributed under the terms of the Creative Commons Attribution License (type CC-BY), which permits unrestricted use, distribution and reproduction in any medium, provided the original article is properly cited. 